\title{
L2 Korean Speakers' Thematic Role Resolution in a Psych-predicate Construction
}

Hyunah Ahn $^{\dagger}$

Seoul National University

\begin{abstract}
This study investigated how second language (L2) and heritage Korean learners whose first language (L1) is English identify an ambiguous thematic role (experiencer vs. stimulus) of a null argument psych-predicate construction in Korean. Participants listened to stories where a null argument construction such as 'Iwummeituka munsewun ka poayo' (The roommate must be afraid of $\varnothing$ vs. The roommate must be scary) was disambiguated contextually with matching and mismatching prosodies and answered comprehension questions that asked to identify the thematic role of an overt NP. Advanced- level learners were more accurate and faster in identifying a stimulus, preferred Accentual Phrases that accompany the stimulus reading, and showed an interaction between thematic role and prosody. An independent analysis also showed that the preference for stimulus reading could be attributed to the advanced learners being heritage Korean speakers. Hypotheses on different roles of L1 and heritage grammar are discussed in light of the results.
\end{abstract}

Keywords: null arguments in L2 Korean, psychological predicates, thematic roles, double-nominative construction, discourse syntax interface

\section{Introduction}

When second language (L2) learners encounter a grammatical construction in their new language, relying on their first language (L1) grammar or processing routine is one of the most common routes they take to make meaning out of the unfamiliar construction. The so-called L1 transfer or L1 influence has been the most researched topic in second language acquisition. The traditional and strong version of L1 influence is not accepted any more that the linguistic distance between the first and target languages will predict the extent to which learners will experience difficulty learning a second language (Lado, 1957); nevertheless, the role of L1

\footnotetext{
* This research was funded by a Elizabeth Carr-Holmes scholarship in the Department of Second Language Studies at the University of Hawaii at Manoa.

† Corresponding author: prosodygal@snu.ac.kr
} 
grammar in the acquisition and processing of L2 grammar is still avidly investigated by researchers of all theoretical orientations. The investigations are not limited to persistent traces of a first language on L2 phonology (Flege, 2002; Flege \& Wang, 1989; Flege, Yeni-Komshian \& Liu, 1999); an extensive variety of research was conducted on L1 influence on the acquisition of L2 syntax and semantics (Morett \& MacWhinney, 2012; Scheidnes, Tuller \& Delage, 2009; Slabakova, 2000).

Among such investigations on L1 influence on L2 syntax and semantics, only a small number of studies have looked into the combination of L1 English and L2 Korean, and even fewer studies looked into L1 influence on a phenomenon at the interface of syntax, discourse, and prosody in L2 Korean. In the current study, we investigated how English as an L1 or additional language that learners grow up with in a bilingual environment can influence the way they identify an ambiguous thematic role in a null argument construction in L2 Korean.

\section{Background and Motivation}

\subsection{Psychological predicates in English and Korean}

Two-place psychological verbs (psych-verbs henceforth) can be categorized into three classes based on what thematic roles are required and how the thematic roles are realized grammatically (Belletti \& Rizzi, 1988; Landau, 2010). Namely, the (1) temere, (2) preoccupare, and (3) piacere types of verbs require the thematic roles of experiencer and stimulus, and the grammatical case each thematic role is assigned to differs as in the following examples.

Class I verbs (1) have the experiencer and stimulus marked with nominative and accusative cases, respectively, whereas those in class II (2) have the case marking reversed for the two thematic roles. Lastly, class III verbs (3) have the stimulus marked with the nominative case and the experiencer with the dative case.

(1) The temere type: Class I

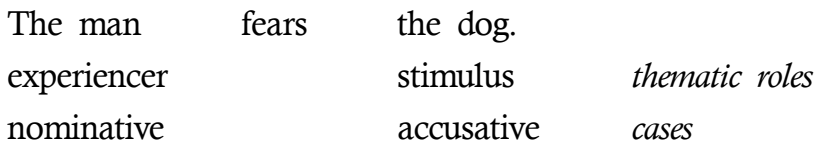


(2) The preoccupare type: Class II

The news worried him.

$\begin{array}{ll}\text { stimulus } & \text { experiencer thematic roles } \\ \text { nominative } & \text { accusative cases }\end{array}$

(3) The piacere type: Class III The movie appealed to the audience.

$\begin{array}{lll}\text { stimulus } & \text { experiencer } & \text { thematic roles } \\ \text { nominative } & \text { dative } & \text { cases }\end{array}$

To second language (L2) learners, the mapping of thematic roles and grammatical cases could be a source of confusion in that such mappings differ greatly from language to language. In Korean, many psychological predicates (psych-predicates) come in the form of adjectives and used as is, or they are turned into transitive verb phrases with the $-e$ hata or -key hata endings. For example, the psych-adjective mwusep- in Korean, in its canonical form, belongs to class III as in (4)1). With the - hata ending (5), it takes a nominative experiencer and an accusative stimulus (class I), and with the -key hata ending (6), it takes a nominative stimulus and an accusative experiencer (class II).

$\begin{array}{lll}\text { (4) Na-eykey(-nun) } & \text { Tom-i } & \text { mwusep-ta. } \\ \text { I-DAT(-TOP) } & \text { Tom-NOM } & \text { scary-DEC }\end{array}$

"To me, Tom is scary." Class III

\begin{tabular}{|c|c|c|}
\hline (5) Nay-ka & Tom-ul & mwusewu-e-hanta \\
\hline I-NOM & Tom-ACC & scary-e-hanta \\
\hline
\end{tabular}

$\begin{array}{lll}\text { (6) Nay-ka } & \text { Jim-ul } & \text { mwusep-key-hanta. } \\ \text { I-NOM } & \text { Jim-ACC } & \text { scary-causative-DEC } \\ \text { "I scare Jim." } & \text { Class II }\end{array}$

1) One might argue that the piacere type in (3) and the Korean dative-experiencer psych-predicate in (4) are not structural equivalents to each other. However, Belletti and Rizzi (1988) discusses in detail that both of the Italian sentences "A Gianni piace questo (To Gianni pleases this)" and "Questo piace a Gianni (This pleases to Gianni)" originate from the same underlying structure and that such freedom is allowed only in psych-verbs. They also explain that "He is scary for me" is a class III construction while "He scares me" is class II. Therefore, it seems appropriate to classify the 'mwusep-' type of psych-predicates in Korean into class III. 
The morphological marking of thematic roles, however, is not always obvious in that Korean allows the double nominative construction. That is, the originally, class III psych-predicate mwusep- can take a nominative experiencer and a nominative stimulus (7). In such cases, it is the word order that clarifies the thematic roles of the two arguments. The experiencer should come before the stimulus when both are marked nominative.
(7) Jim-i
Tom-i
mwuse-wun-ka
po-ta.
Jim-NOM Tom-NOM
scary-PRES-SAI2)
$\mathrm{po}^{3)}-\mathrm{DEC}$
"Jim must be scared of Tom."

Finally, Korean allows a null argument within contexts. That is, depending on the information structure of a discourse, one or both of the arguments can be dropped. The sentence in (8) has only one overt argument and it is impossible to tell without a larger context whether it is the experiencer or the stimulus that was omitted from the original sentence. Native Koreans can identify the thematic role of the overt argument in (8) based on the context. For example, in (9), Tom is running away because he is afraid of Jack, which makes Tom the experiencer and Jack in (9B) the stimulus of the psychological predicate mwusep-. The NP Tom is not overtly realized in (9B) because it is given information from the previous sentence. As given information in English is realized as unstressed pronouns, given NPs are often realized as null NPs in Korean (Gundel, Hedberg \& Zacharski, 1993).

(8) Jack-i mwuse-wun-ka po-ta

Jack-NOM scary-PRES-SAI po-DEC

(9) A: Why is Tom running away?

B: Jack-i mwusewu-nka po-ta.

Jack-NOM afraid- PRES-SAI po-DEC

"(Tom) must be afraid of Jack."

2) Self-addressed interrogative

3) The inferential evidentiality marker 'po' was used because asserting a third person's psychological experience is deemed pragmatically infelicitous in Korean. 
(10) A: Why did you leave the light on?

B: Jack-i mwuse-wun-ka po-a, kkuci malako hayss-e. Jack-NOM afraid-PRES-SAI po-DEC, turn-off not PST-DEC "Jack must be afraid (of dark), (he) said not to turn (it) off."

$\begin{array}{clll}\text { (11) a. (Tom-i) } & \text { Jack-i } & \text { mwuse-wun-ka } & \text { po-ta. } \\ \text { b. Jack-i } & \text { (etwum-i) } & \text { mwuse-wun-ka } & \text { po-ta. }\end{array}$

Another example is given in (10), when A asked B why the light is left on, B says Jack wanted it on and B is guessing that Jack must be afraid of the dark. Here, Jack is the experiencer, and the dark is the stimulus of the fear. (11) shows how the apparently identical sentence can come from two different sources. If an inanimate NP is the only overt NP, one can use the inanimacy of the NP to assume that the NP is the stimulus since we assume that only animate entities can be the experiencer of a psychological state. But when the only overt NP is animate, the ambiguity needs to be resolved through context because an animate entity can both experience and stimulate a psychological state in another animate entity.

The relationship between the animacy and the thematic role of an NP will not differ across languages since it belongs to the realm of real-world knowledge. The relationship is also valid in English. Table 1 shows the ratio of human NP collocates for class II psych-verbs in English. In the Corpus Of Contemporary American English (Davies, 2008-), NP collocates were searched for the past and present participle forms of the psych-verbs in the first column of Table 1. The corpus does not have NPs tagged for their thematic roles, and the collocates were searched within the range of three words before and after the psych-verbs. The table shows that $50 \%$ of the NP collocates for the past participle forms can be human NPs. However, a non-human NP cannot be the experiencer of a psychological state. In sentences with inanimate collocates for past participle forms such as 'annoyed' or 'disappointed,' the inanimate NPs usually indicated the stimulus of the psych-verbs. 
Table 1. The ratio of human NP collocates for past and present participles of Class II Psych-verbs in English from COCA

\begin{tabular}{cccccccc}
\hline & \multicolumn{3}{c}{ Past participle } & & \multicolumn{3}{c}{ Present participle } \\
\cline { 6 - 7 } \cline { 5 - 7 } Verb root & Human NP & $\begin{array}{c}\text { Total } \\
\text { occurrences }\end{array}$ & Ratio & & Human NP & $\begin{array}{c}\text { Total } \\
\text { occurrences }\end{array}$ & Ratio \\
\hline \hline Annoy & 233 & 613 & $38 \%$ & 271 & 1,108 & $24 \%$ \\
Disappoint & 839 & 1,614 & $52 \%$ & & 54 & 1,568 & $3 \%$ \\
Disgust & 131 & 526 & $25 \%$ & & 125 & 725 & $17 \%$ \\
Embarrass & 487 & 1,166 & $42 \%$ & & 124 & 1,576 & $8 \%$ \\
Frighten & 962 & 1,565 & $61 \%$ & & 177 & 1,747 & $10 \%$ \\
Frustrate & 1,259 & 2,571 & $49 \%$ & & 147 & 1,411 & $10 \%$ \\
Interest & 5,519 & 10,564 & $52 \%$ & & 1,770 & 17,738 & $10 \%$ \\
Please & 611 & 1,863 & $33 \%$ & & 63 & 897 & $7 \%$ \\
Satisfy & 743 & 1,618 & $46 \%$ & & 54 & 1,626 & $3 \%$ \\
Surprise & 1,787 & 3,215 & $56 \%$ & 515 & 4,397 & $12 \%$ \\
\hline Total & 12,571 & 25,315 & $50 \%$ & 3,300 & 32,793 & $10 \%$ \\
\hline
\end{tabular}

What is noteworthy in the data above is the ratio of human NPs between past and present participle forms of the verbs. The past participle form of a psych-verb (e.g., 'embarrassed') requires an experiencer NP whereas its present participle counterpart 'embarrassing' will require a stimulus NP. The relationship between the morphological form of a psych-verb and the thematic role of the NP that the verb modifies is well depicted by the percentage of human NP collocates in the past participle forms (50\%) and the present participle forms (10\%).

This discrepancy in the human NP ratio implies that English speakers will more likely to interpret a human NP to be an experiencer of a psych-verb than a stimulus. The tendency, in turn, will influence the way they interpret an ambiguous construction as in (8) in Korean. One should note that L1-English L2-Korean learners cannot transfer the morphological distinction of frightened and frightening into Korean. What they can transfer is the relationship between a nominative-marked animate NP and a psych-predicate. Since Korean does not have morphological markings on psych-predicates, L2 Korean speakers whose L1 is English will use their L1 processing strategy to interpret the thematic role of a human NP as an experiencer.

This discrepancy between English psych-verbs and Korean psych-predicates alone can be a source of great difficulty when English speakers attempt to learn Korean. The challenge does not end there. Previous studies (Ahn, 2017; 2018) show that 
Koreans also use prosody to distinguish the two different meanings of the ambiguous construction.

\subsection{Korean Prosody}

Korean prosody is characterized by a variety of levels of phrasing and boundary tones (Jun, 1993; 2005; 2007; Jun \& Cha, 2015). One or more prosodic words form an accentual phrase (AP), which, in turn, constitutes a larger prosodic unit, an intermediate phrase (ip), by itself or in groups with other APs. The ip, then, forms an Intonational Phrase (IP) by itself or with other ip's. In brief, the prosodic breaks can be ordered AP < ip < IP from the smallest to the greatest breaks.

$\begin{array}{lllll} & \text { Tom-i } & \text { Jim-i } & \text { mwusewu-nka } & \text { po-a-yo } \\ \text { a. } & {\left[[\text { Tom-i }]_{\mathrm{AP}}\right.} & {[\mathrm{Jim}-\mathrm{i}]_{\mathrm{AP}}} & {[\text { mwusewu-nka }} & \left.\text { po-a-yo }]_{\mathrm{AP}}\right]_{\mathrm{IP}} \\ \text { b. } & {\left[[\text { Tom-i }]_{\mathrm{AP}}\right]_{\mathrm{IP}}} & {\left[[\mathrm{J} \text { Jim-i }]_{\mathrm{AP}}\right.} & {[\text { mwusewu-nka }} & \left.\text { po-a-yo }]_{\mathrm{AP}}\right]_{\mathrm{IP}}\end{array}$

In uttering a sentence like (12), each word (e.g., Tom-i) or a phrase with more than one words (e.g., mwusewun ka poayo) can form an AP. Because a larger syntactic unit is often accompanied by a larger prosodic unit (Hwang \& Steinhauer, 2013; Jun, 2003), it is highly unlikely for a smaller prosodic break to be used between the first NP and the second NP than between the second NP and the VP in (12). This leads to the hypothesis that for an ambiguous sentence as in (8), the experiencer reading can have either a smaller break (AP) or a larger break (IP) while the stimulus reading will more likely have a smaller break (AP). Indeed, this hypothesis was tested in Ahn (2017), and the study showed that the ambiguous construction in (8) can be prosodically distinguishable. Native Korean speakers found the stimulus reading of the ambiguous construction natural only when it is accompanied by a relatively smaller prosodic break (AP) while they found the experiencer reading natural either with AP or IP breaks.

\subsection{Second Language Prosody}

Many studies on second language phonology focuses on the influence of learners' first language on the segmental production and perception of English as a second language (Flege et al., 2006; Kwon, 2017; Tsukada et al., 2005). A handful of studies on suprasegmentals focused mainly on how foreign accented a learner was (Trofimovich 
\& Baker, 2005). Rarely has there been a study on the interface between prosody, syntax and discourse in second language processing (c.f., L2 German prosody in Jackson \& Carrie, 2011).

As for L2 Korean prosody, Jun and Oh (2000) reported that native English speakers experienced difficulty using prosody to mark syntactic and semantic differences in Korean. (13) shows an example of how a segmentally identical sentence can be prosodically distinguished for two different meanings. Korean uses prosodic phrasing to disambiguate the global ambiguity of the sentence (13).

English native speakers experienced difficulty putting two words into one AP (13a) and producing a natural prosody for the wh- question while they could produce separate APs for each question (13b). However, their success in creating the yes/no prosody could be due to their phonological inability to putting more than one words into an $\mathrm{AP}$.

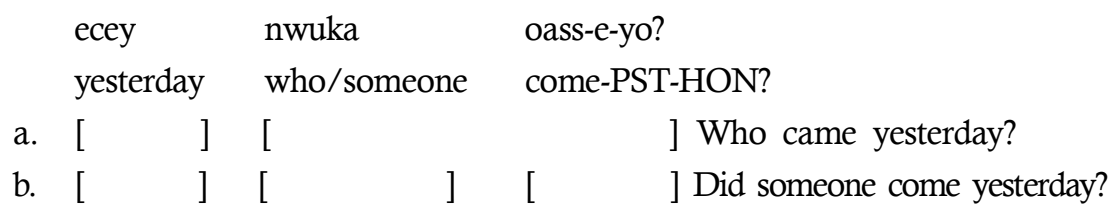

Since there are not many studies that investigate the use of prosody in L2 Korean sentence processing, one cannot make a clear prediction in terms of what implications, the findings from Jun and Oh (2000) will have for the purpose of the current study that L2 Korean speakers might find it easy to produce single-word APs than multi-word APs. A rather speculative hypothesis one can formulate will be that L2 speakers might be familiar with AP boundary tones.

\subsection{Research Questions and Predictions}

Resolving the ambiguity of the construction (8) 'Jim-i mwusewn-n ka po-a-yo' requires syntax, semantics, and prosody on their interface and poses a set of challenges to those who learn Korean as a second language. From what has been discussed so far, one can postulate the following possibilities.

One is that native English speakers who learn Korean as a second language might transfer the knowledge of their L1 argument structure to resolve the ambiguity of (8). Since nominative animate NPs accompanying English psych-verbs are more likely to be the experiencer, English speakers might try to interpret the overt 
argument in (8) to be the experiencer. This is especially plausible if the ambiguous construction is given without a context.

Another possibility is that English speakers might use the situational contexts to resolve the ambiguity with regard to the thematic role. Even if the typical interpretation of the ambiguous construction (8) is the experiencer reading in English, English also alternates the use of referential NPs and pronouns in response to the discourse structure (Gordon, Grosz, \& Gilliom, 1993; Grosz, Joshi, \& Weinstein, 1995). Then, the disambiguation of the sentence might depend on the context.

Lastly, English learners of Korean might have some sensitivity to different prosodic phrasings. Although learners at a lower-level proficiency (or even at an advanced level) might not have a target-like mapping between syntax and prosody, they might notice different prosodic breaks. Especially with the previous findings that show L2 speakers' familiarity with Accentual Phrases, it will be worthwhile to investigate if L2 speakers will show sensitivity to AP and IP boundary tones that accompany different meanings of the construction. With these possibilities in view, the current study attempts to answer the following questions.

Q1. Will English L2 speakers transfer their L1 knowledge and interpret the ambiguous construction as experiencer reading more often than as stimulus reading? Or will they rely on situational contexts to interpret the thematic role of the overt NP?

Q2. Will L1-English L2-Korean speakers respond to matching and mismatching prosodies to each interpretation of the ambiguous construction as native Koreans do?

\section{Method}

\subsection{Participants}

Data were collected from eighteen participants, a half of whom were heritage speakers of Korean who were born and raised in the U.S. and spoke Korean at home. The other half of the participants were second language learners of Korean, who also spoke only English as their dominant language and whose Korean learning mostly occurred in classroom settings. 


\subsection{Stimulus}

Experiment items were borrowed from Ahn (2017). Each ambiguous construction was contextualized as in (14) and (15), which prevented any native speaker of Korean from experiencing difficulty in identifying the thematic role of the critical NP roommate. The critical sentence 'wummeitu ka mwusewun ka poayo' in (14d) and (15d) was contextualized such that in one story the roommate is the experiencer (14) and in the other story the stimulus (15). Then, the stories had the critical sentence read with a larger prosodic break (an IP boundary) and a small prosodic break (an AP boundary) for the experiencer and the stimulus contexts, respectively. Figures 1 and 2 show IP and AP tones on the nominative marker $-k a$, respectively.

(14) Experiencer context $\left.{ }^{4}\right)$
a. Yenga's roommate went out in Yenga's shoes without asking.
b. In the evening, the roommate came home.
c. Yenga got angry and started screaming.
d. Lwummeitu-ka mwusewu-n ka pwa-yo.
('The roommate must be scared.')
e. She's being quiet not knowing what to say.

Comprehension Q.5) Who went out in the other's shoes without asking?
(a) Yenga
(b) Roommate

(15) Stimulus context
a. Yenga and the roommate are having a big fight.
b. The roommate lost her temper and started screaming.
c. Yenga is walking backwards away from the roommate.
d. Lwummeitu-ka mwusewu-n ka pwa-yo
('The roommate must be scary.')
e. (Yenga) went into the bedroom and locked the door inside.

Comprehension Q. Who's retreating into the bedroom?
(a) Yenga
(b) Roommate

4) All items and questions were given in Korean. The contextual sentences and comprehension questions were translated to English for limited space.

5) Comprehension questions were given on the screen in the written form. Participants were asked to press a button for either (a) or (b) as quickly as possible. 


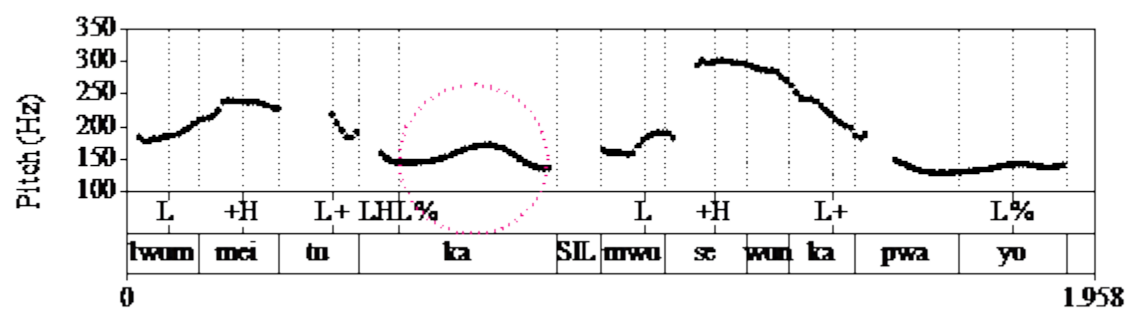

Time (s)

Figure 1. A prosodic contour of an IP break on the nominative marker $-k a$

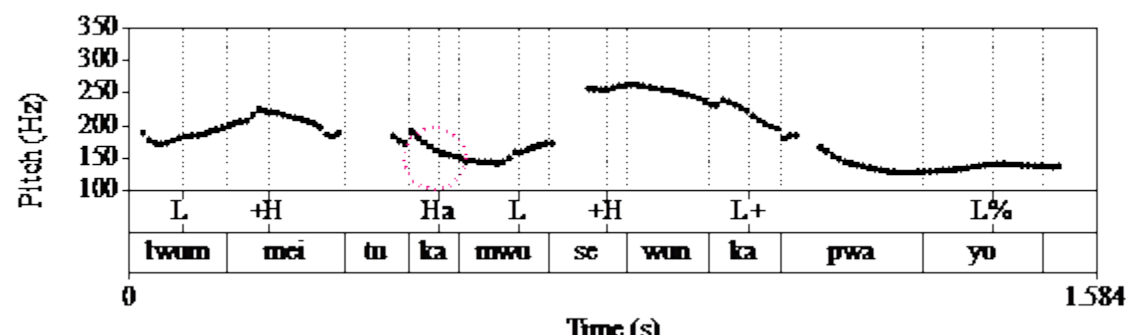

Figure 2. A prosodic contour of an AP break on the nominative marker $-k a$

To examine the effect of prosody, Ahn (2017) spliced the recordings of the critical sentence in the two stories to create four different versions for each item. The 2 thematic roles $\mathrm{x} 2$ prosodies design was Latin-squared into four lists so no item will be repeated through more than one condition.

\subsection{Procedure}

When participants arrived in the lab, they first filled out a background questionnaire and took a c-test for proficiency measurement. The c-test had 125 blanks, each of which was scored 0,1 , or 2 depending on the number of syllables they answered correctly. The maximum score of the test was 242 and the participants were grouped into intermediate ( $\mathrm{N}=8$, c-test accuracy: $22 \%$ ) and advanced $(\mathrm{N}=10$, c-test: $61 \%$ ) learners based on the percentage of accurate responses to the test. The two groups' c-test scores were statistically significant $(t=-6.51, \mathrm{df}=10.99, p<.001)$. Seven out of 10 participants in the advanced group were heritage Korean speakers.

After the c-test, participants were seated in a sound-attenuated booth and given instructions on how to answer each item. For each item, participants were asked 
to listen to stories and rate the naturalness of each sentence as they heard it. After each story was a comprehension question to probe whether they correctly interpreted the thematic role of the single overt NP in the ambiguous construction. When naturalness was rated and comprehension questions were answered, the corresponding reaction times (RTs) were also measured.

\subsection{Analysis}

For analysis, R packages tidyverse (Wickham et al., 2019), lme4 (Bates, Maechler, Bolker, \& Walker, 2015) and lmerTest (Kuznetsova, Brockhoff, \& Christensen, 2017) were used to manage data, run statistical models, and test the significance of null hypotheses. For naturalness ratings, RTs to naturalness ratings, and RTs to comprehension questions, linear mixed effects regression was used; and for responses to comprehension questions, logistic mixed effects regression was used.

\section{Results}

The results of the data analyses were different from what was predicted and also from native Korean speakers' behavior reported in Ahn (2017). Naturalness ratings and RTs to naturalness ratings did not yield any significant differences between conditions, most likely due to the small data size. The accuracy of responses to comprehension questions and the corresponding RTs resulted in interesting, if unexpected, patterns. Below we report the results of the analyses on comprehension question data.

\subsection{Analysis by proficiency group}

\subsubsection{Accuracy of responses to comprehension questions}

To analyze the accuracy of responses to comprehension questions, all participants' data were analyzed in a logistic mixed effects regression model with thematic roles, prosody, and group as fixed effects with items and participants as random effects. Due to the small size of data, a full model with the maximal structure of random effects failed to converge random effects structures were reduced stepwise, and models with only random intercepts were selected based on the AIC/BIC values of the models (Barr, Levy, \& Scheepers, 2013; Matuschek, Kliegl, Vasishth, Baayen, 
\& Bates, 2017). Table 2 summarizes the output of the model. It resulted in a main effect of group, an interaction effect of prosody and group, and an interaction effect of thematic role, prosody, and group. Also, there was a marginal main effect of thematic role. Figure 3 shows that there was a clear discrepancy not only between groups, but in the patterns in which each group was accurate in responses to comprehension questions for different combinations of thematic role and prosody. To delve into the different patterns, separate analyses were conducted for the high proficiency group.

Table 2. Fixed effects of logistic mixed effects regression of comprehension question accuracy of all participants.

\begin{tabular}{lcccc}
\hline & Estimate & Std. Error & $\mathrm{z}$ value & $\operatorname{Pr}(>|\mathrm{z}|)$ \\
\hline \hline Intercept) & 1.348 & 0.220 & 6.127 & $0.000^{* * *}$ \\
\hline Thematic role & -0.324 & 0.172 & -1.881 & 0.060 \\
\hline Prosody & 0.235 & 0.171 & 1.369 & 0.171 \\
\hline Group & 0.813 & 0.173 & 4.699 & $0.000^{* * *}$ \\
\hline $\begin{array}{l}\text { Thematic role } \\
\quad \times \text { prosody }\end{array}$ & -0.174 & 0.172 & -1.012 & 0.311 \\
\hline $\begin{array}{l}\text { Thematic role } \\
\times \text { group }\end{array}$ & -0.280 & 0.174 & -1.608 & 0.108 \\
\hline $\begin{array}{l}\text { Prosody } \\
\quad \times \text { group }\end{array}$ & 0.450 & 0.173 & 2.597 & $0.009^{* *}$ \\
\hline $\begin{array}{l}\text { Thematic role } \\
\times \text { prosody } \times \text { group }\end{array}$ & -0.438 & 0.175 & -2.508 & $0.012^{*}$ \\
\hline
\end{tabular}

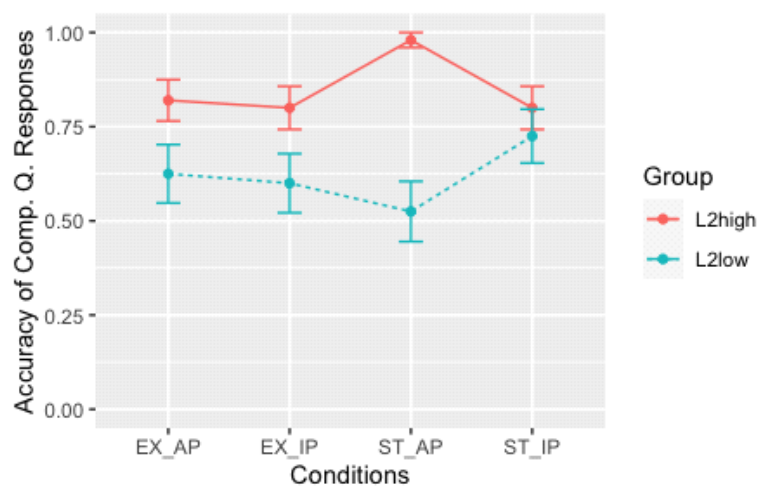

Figure 3. Accuracy of responses to comprehension questions by condition and by proficiency group. 
Table 3 summarizes the accuracy rate of responses to comprehension questions in each condition by group, and Table 4 summarizes the output of a logistic mixed effects regression model that analyzed the high proficiency group only.

Table 3. Accuracy rate of responses to comprehension questions by condition and group

\begin{tabular}{cccc}
\hline Thematic role & Prosody & L2 high & L2 low \\
\hline \hline Experiencer & AP & 0.82 & 0.63 \\
Experiencer & IP & 0.80 & 0.60 \\
Stimulus & AP & 0.98 & 0.53 \\
Stimulus & IP & 0.80 & 0.73 \\
\hline
\end{tabular}

Table 4. Fixed effects of logistic mixed effects regression of comprehension question accuracy of high proficiency group

\begin{tabular}{lrcrl}
\hline & Estimate & Std. Error & $\mathrm{z}$ value & $\operatorname{Pr}(>|\mathrm{z}|)$ \\
\hline \hline (Intercept) & 2.0712 & 0.3197 & 6.478 & $9.30 \mathrm{E}-11^{* * *}$ \\
Thematic role & -0.5911 & 0.2982 & -1.983 & $0.0474^{*}$ \\
Prosody & 0.6653 & 0.2981 & 2.232 & $0.0256^{*}$ \\
Thematic role $\times$ prosody & -0.5937 & 0.298 & -1.992 & $0.0464^{*}$ \\
\hline
\end{tabular}

From Tables 3 and 4, one can see that advanced learners showed higher accuracy in responses to comprehension question in the stimulus condition. They also showed higher accuracy in the AP condition than in the IP condition. The main effects, however, seemed to mainly come from the stimulus-AP condition. A pairwise comparison analysis showed that the stimulus-AP condition has a marginally higher accuracy in comprehension questions than the stimulus-IP condition $(\beta=-2.518$, $s e=1.073, z=-2.346, p=0.081)$ and the experiencer-IP condition $(\beta=-2.513$, $s e=1.073$, $z=-2.343, p=0.081)$. In all the other pairs of comparisons, the differences were insignificant.

\subsubsection{Reaction Times (RTs) to comprehension questions}

Reaction Time (RT) data were analyzed using linear mixed effects regression models. Since raw RT data were highly skewed (skewness=3.06) and insensitive to changes between conditions, RTs were transformed into logarithms. Figure 4 shows that the low proficiency group took longer RTs in general than the high proficiency group. The log-transformed values (skewness $=0.28$ ) were then used as the dependent 
variable for a linear mixed effects regression model with thematic role, prosody, and group as fixed effects and items and participants as random effects. Again, the small size of data resulted in convergence failures, and only intercepts were included for random factors. A main effect of thematic role and a main effect of group was found. Participants took significantly longer to respond to comprehension questions when the question was to identify an experiencer, and the low proficiency group took a significantly longer time to respond to comprehension questions than the high proficiency group.

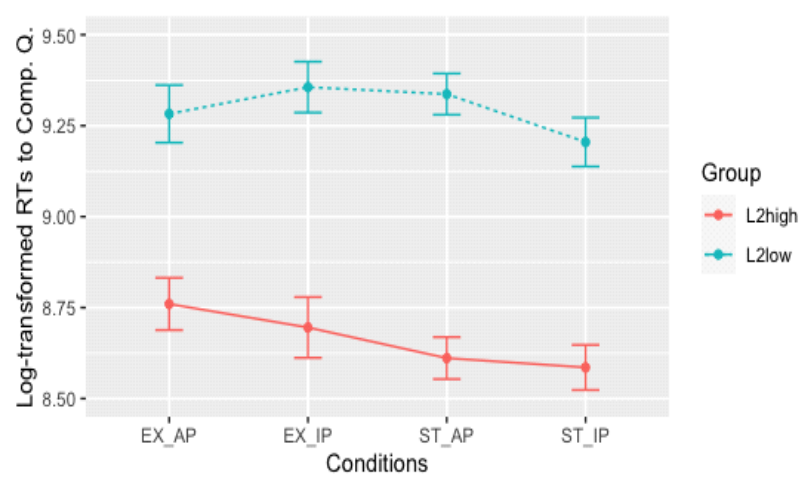

Figure 4. Log-transformed RTs to Comprehension Questions by condition and by proficiency group.

Table 5. Fixed effects of linear mixed effects regression of log-transformed RTs to comprehension questions.

\begin{tabular}{lcccc}
\hline & Estimate & Std. Error & $t$ value & $\operatorname{Pr}(>|\mathrm{t}|)$ \\
\hline \hline Intercept) & 8.979 & 0.067 & 134.645 & $<2 \mathrm{e}-16^{* * *}$ \\
\hline Thematic role & 0.047 & 0.021 & 2.290 & $0.023^{*}$ \\
\hline Prosody & 0.019 & 0.020 & 0.947 & 0.344 \\
\hline Group & -0.316 & 0.057 & -5.509 & $0.000^{* * *}$ \\
\hline $\begin{array}{l}\text { Thematic role } \\
\times \text { prosody }\end{array}$ & -0.018 & 0.021 & -0.885 & 0.377 \\
$\begin{array}{l}\text { Thematic role } \\
\times \text { group }\end{array}$ & 0.028 & 0.021 & 1.308 & 0.192 \\
\hline $\begin{array}{l}\text { Prosody } \\
\times \text { group }\end{array}$ & -0.004 & 0.021 & -0.177 & 0.860 \\
\hline $\begin{array}{l}\text { Thematic role } \\
\times \text { prosody } \times \text { group }\end{array}$ & 0.034 & 0.021 & 1.595 & 0.112 \\
\hline
\end{tabular}


Although there was no interaction of thematic role and group, a separate analysis was conducted to ensure that the high proficiency group took longer to process the experiencer reading of the ambiguous construction. Table 6 summarizes the fixed effects output of a linear mixed effects regression model fit to the high proficiency group data with thematic role and prosody as fixed effects and item and participant for random intercepts.

Table 6. Fixed effects of linear mixed effects regression of RTs to comprehension question of high proficiency group

\begin{tabular}{lcccc}
\hline & Estimate & Std. Error & $t$ value & $\operatorname{Pr}(>|\mathrm{t}|)$ \\
\hline \hline Intercept) & 8.663 & 0.096 & 90.638 & $<2 \mathrm{e}-16^{* * *}$ \\
\hline Thematic role & 0.073 & 0.029 & 2.506 & $0.013^{*}$ \\
\hline Prosody & 0.017 & 0.027 & 0.602 & 0.548 \\
\hline Thematic $\times$ prosody & 0.015 & 0.029 & 0.514 & 0.608 \\
\hline
\end{tabular}

Separate analyses on the low proficiency group resulted in no significance in any of the main or interaction effects for comprehension question accuracy. As for RTs to comprehension questions, the low proficiency group also took significantly longer to respond to comprehension questions when they asked to identify an experiencer.

\subsection{Analysis by heritage group}

\subsubsection{Accuracy of responses to comprehension questions}

The high proficiency group scoring higher in the stimulus reading was unexpected, and it was necessary to probe whether this unexpected result could have come from the fact that the high proficiency group was mostly made up of heritage speakers, not just L2 speakers.

To answer the question, another analysis was conducted with the heritage group as a fixed factor. When grouping was done by heritage, the heritage group had 9 participants, 2 of which did not belong to the high proficiency group in proficiency grouping, and the non-heritage group had 9 participants, 6 of which did not belong to the high proficiency group in the previous grouping. Figure 5 visualizes the comprehension question accuracy by condition and by heritage group. It has the same pattern as that of accuracy rate changes by condition and by proficiency group shown in Figure 3. Table 7 also shows that a main effect of heritage group and 
an interaction effect of thematic role and heritage group are significant.

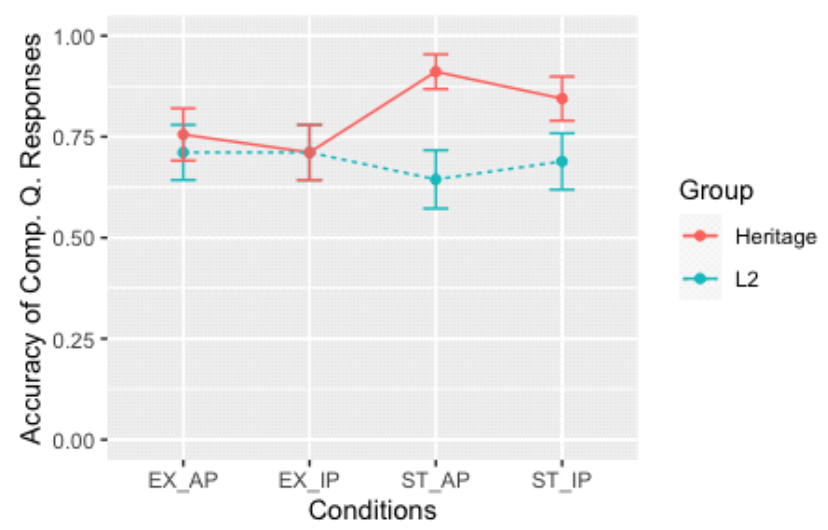

Figure 5. Accuracy rate of response to comprehension questions by condition and by heritage group.

Table 7. Fixed effects of logistic mixed effects regression of accuracy rates to comprehension questions of all data

\begin{tabular}{lcccc}
\hline & Estimate & Std. Error & $\mathrm{z}$ value & $\operatorname{Pr}(>|\mathrm{z}|)$ \\
\hline \hline Intercept) & 0.876 & 0.254 & 3.455 & $0.001^{\text {*** }}$ \\
\hline Thematic role & 0.111 & 0.168 & 0.664 & 0.507 \\
\hline Prosody & -0.056 & 0.168 & -0.332 & 0.740 \\
\hline Heritage & 0.783 & 0.339 & 2.313 & $0.021^{*}$ \\
\hline Thematic role $\times$ prosody & 0.058 & 0.168 & 0.345 & 0.730 \\
\hline Thematic role $\times$ heritage & -0.643 & 0.270 & -2.385 & $0.017^{*}$ \\
\hline Prosody $\times$ heritage & 0.285 & 0.268 & 1.063 & 0.288 \\
\hline Thematic role $\times$ prosody $\times$ heritage & -0.153 & 0.268 & -0.572 & 0.567 \\
\hline
\end{tabular}

To probe whether the higher accuracy rate observed in the stimulus reading can be attributable to the fact that seven out of 10 high proficiency participants were heritage speakers, a separate logistic mixed effects regression model was fit only with heritage speakers. Table 8 summarizes the model output. What was interesting in the analysis results of heritage speaker data is that only a main effect of thematic role was observed unlike the high proficiency group data that also had a main effect of prosody and an interaction effect of thematic role and prosody (see Table 4). In pairwise comparisons, only a marginal difference was observed between the 
Stimulus-AP condition and the Experiencer-IP condition $(\beta=-1.516, s e=0.632, z=$ $-2.400, p=0.076)$.

Table 8. Fixed effects of logistic mixed effects regression of comprehension accuracy of the heritage speaker group

\begin{tabular}{lcccc}
\hline & Estimate & Std. Error & $\mathrm{z}$ value & $\operatorname{Pr}(>|\mathrm{z}|)$ \\
\hline \hline (Intercept) & 1.758 & 0.389 & 4.514 & $0.000^{* * *}$ \\
\hline Thematic role & -0.544 & 0.221 & -2.464 & $0.014^{*}$ \\
\hline Prosody & 0.238 & 0.217 & 1.097 & 0.273 \\
\hline Thematic role $\times$ prosody & -0.095 & 0.218 & -0.434 & 0.665 \\
\hline
\end{tabular}

\subsubsection{RTs to comprehension questions}

RTs to respond to comprehension questions were also analyzed. Figure 6 shows that heritage speakers were faster than non-heritage L2 speakers in responding to comprehension questions. Again, to improve the normality of the highly skewed raw RT data, log transformation was used. The transformed logarithms were then put in as the dependent variable of the linear mixed effects regression model that initially included all data. The only significant effect was the main effect of group $(\beta=-0.393$, $s e=0.167, z=-2.348, p=0.032$ ). Heritage speakers were significantly faster to respond to comprehension questions than non-heritage L2 speakers.

Unlike in the by-proficiency analysis (see Table 5), there was no other significant effect observed. The data were still divided into heritage and non-heritage L2 groups, and a separate analysis was conducted on the heritage group. A main effect of thematic role $(\beta=0.054, s e=0.025, \quad z=2.148, \quad p=0.033)$ was observed in the heritage-only analysis, and heritage speakers responded significantly faster to stimulus reading sentences, which was also observed in the high proficiency group.

The results of the heritage group analysis suggest that the unexpected high accuracy in the stimulus condition observed in the high proficiency L2 group could be attributed to the fact that $70 \%$ of the group were heritage Korean speakers. We will further discuss in the next section as to what would lead heritage speakers to interpret the overt NP of the ambiguous construction to be a stimulus. 


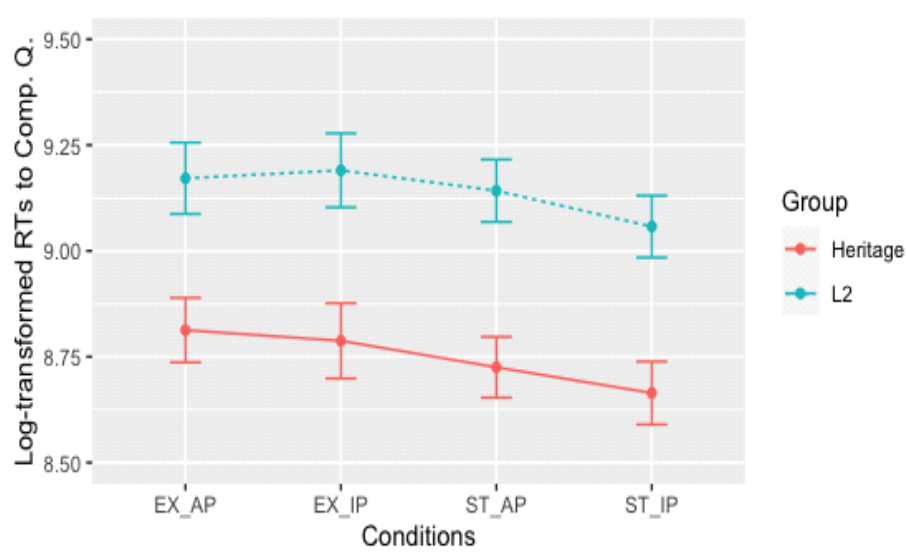

Figure 6. Log transformed RTs to comprehension questions by condition and heritage group.

\section{Discussion}

The current study attempted to investigate whether L2 Korean learners whose L1 is English will transfer their L1 argument structure, use situational contexts, and/or show sensitivity to the mapping between prosody and syntax in their attempt to identify the thematic role of a psych-predicate construction. The results show that L1-English L2-Korean learners do not transfer their L1 grammar or interpret the overt NP to be an experiencer across the board.

First, L2 speakers showed higher accuracy when they were asked to identify a stimulus of a psychological state. Secondly, they also responded more quickly when they were asked to identify a stimulus. The higher accuracy and faster reaction indicate that learners did not transfer from their L1 to treat the Korean psych-predicates as Class II psych-verbs.

Furthermore, they did not seem to use situational contexts either. If they had used situational contexts to identify the thematic role of the construction, a significant difference between the experiencer and stimulus conditions should not have been observed. Using the situational contexts, they should have been able to figure out the thematic role of the overt NP in both experiencer and stimulus conditions accordingly6).

6) A reviewer pointed out that the difficulty levels of comprehension questions could have been different 
Finally, participants were marginally more accurate and faster in responding to comprehension questions when a sentence of stimulus reading was produced with an AP boundary tone than when it was accompanied by an IP boundary tone or when experiencer reading was produced with an IP boundary. This indicates that L2 learners were sensitive to prosody to some extent, if not to the target-like degree.

The L2 behavior summarized above shows that it deviated from what was predicted based on their L1 grammar, but it also differs from L1 behavior. L1 speakers did not display any main effects of thematic role or prosody in the analysis of comprehension question accuracy. Only an interaction effect of thematic role and prosody was reported. Also, prosody was more helpful in the experiencer condition than in the stimulus condition (see Ahn, 2017 for more details).

Despite the deviation from the target-like behavior, L2 speakers in the current study might have experienced the same processing difficulty as L1 speakers did with regard to the experiencer condition. What was commonly observed between L1 and L2 speakers is the longer reaction time to comprehension questions in the experiencer condition. The longer reaction time to experiencer reading in L1 speakers was interpreted to be related to the change of discourse focus (or discourse center as in the centering theory (Gordon et al., 1993; Grosz et al., 1995). According to the theory, an unstressed pronoun in English continues the existing discourse focus while a definite NP will shift its focus to another referent. In Korean, the equivalents to unstressed pronouns and definite NPs will be null arguments and overt arguments, respectively. That is, when the overt NP was the experiencer of the psychological predicate, the omitted stimulus was the focused entity of the discourse in the previous sentence. With the experiencer NP being overtly realized, the focus of the discourse is shifted, which, according to Ahn (2017), induces a higher processing load than when the existing focus continues. Therefore, one plausible account for L2 behavior in this study-the longer reaction time to experiencer reading and higher accuracy in stimulus reading-is that L2 learners experienced the same type of processing difficulty as that in L1 speakers due to the focus shift in the experiencer condition.

between the experiencer and the stimulus conditions in that the questions accompanying the examples (14) and (15) differed in terms of the distances between in-text cues and the questions. However, 10 of the 20 items had the exactly same questions between the two conditions (e.g., "Who first suggested that they go out for a movie?"), which means there was no systematic difference in the questions such that questions in the experiencer conditions were more difficult. Not only does the logistic mixed effects modeling take into account any variation on the individual item level, a separate item analysis conducted after the reviewer's comment also shows that there was no significant difference between items $(p s<1)$. 
This discourse sensitivity account would have been the only available explanation had the L2 group not been mainly composed of heritage speakers. However, seven among the ten participants of the high proficiency L2 group were heritage speakers. Separate analyses were conducted with the heritage and non-heritage distinction as a group factor, and the results suggested that heritage speakers were better at identifying a stimulus. The results do not necessarily indicate that the higher accuracy in the stimulus condition could not have come from L2 speakers, but it seems reasonable at this point to discuss why heritage speakers, not non-heritage Korean speakers, were better at identifying a stimulus.

There can be two different scenarios in terms of how the two arguments are mapped with thematic roles and grammatical cases in heritage Korean. The first is that heritage speakers have the target-like grammar and understand that the Korean psych-predicates at issue belong to class III in Belletti and Rizzi's (1988) classification. That is, they understand that the psych-predicates can take an animate nominative stimulus unlike their non-heritage L2 counterparts. Since heritage Korean speakers are often exposed to colloquial Korean, which is characterized by common argument drops, it is possible that they are familiar with such psych-predicates being used in a sentence with its dative experiencer omitted.

The other possibility is that heritage speakers interpreted the Korean class III psych-verbs to belong to class II but in a different manner from what was predicted for non-heritage L2 speakers. The assumption in the beginning of this study was that L2 speakers are used to the relationship between the animacy of the nominative NP and the morphological distinction of the psych-verbs that belong to class II in English. Because human NPs were clearly more associated with the past participle form, L2 speakers were expected to interpret the overt NP as the experiencer of the verb. One can postulate that heritage speakers might have used the underlying structure of class II psych-verbs, which requires a nominative stimulus. Although class II psych-verbs in English (e.g., excite, interest, scare, etc.) are commonly used in the participle forms either in verb phrases or as modifiers in noun phrases, it is not impossible to use such verbs in finite forms as the main verb of a sentence as in Jack disappointed Jill or in Tom scares John. Then, it is plausible that heritage speakers interpreted the overt NP of the psych-predicate construction to fill the nominative position with a proto-agent stimulus.7) From this line of reasoning arises

7) According to Dowty (1991), a nominative stimulus and accusative experiencer in class II verbs are equal in their properties to assume the proto-Agent role, but the experiencer makes a better proto-Patient. Therefore, the stimulus takes a proto-Agent status by comparison. 
a question why the results obtained in the present study should be attributed to the fact that a majority of the high proficiency group were heritage speakers. Indeed, it is not impossible that non-heritage L2 speakers might also interpret the critical NP of the construction as the stimulus of the psych-predicate and might use the underlying structure of class II English psych-verbs. For now, the possibility should remain as an empirical question to be answered in a future study.

\section{Conclusion}

The current study showed that L2 Korean speakers of high proficiency were more accurate and reacted faster when they processed the overt NP of a null argument psych-predicate condition to be the stimulus of a psychological state. The results were discussed in light of how the majority of the high proficiency group being heritage speakers could have contributed to the unexpected results. Because the two different groupings were a conflating factor, the results cannot be discussed in conclusive terms. However, assuming that heritage and non-heritage L2 Korean interlanguage grammar can differ, the findings of the current study suggest two possibilities. The first is that the mwusep-type predicate in Korean, which belongs to class III in Belletti and Rizzi's (1988) classification, might also belong to class III in heritage Korean interlanguage and that heritage speakers do understand that a dative experiencer can be omitted. The other is that they might have an L1-influenced representation of a class II verb for Korean class III verbs but might omit the accusative experiencer due to their exposure to colloquial Korean at home.

Due to the small sample size and the conflation of proficiency and heritage groups, some preliminary speculations were unavoidable. However, the questions raised through this study are expected to lead to studies that can delve into L2 development of syntax and semantics. First of all, if the outcome of the current study is indeed attributable to the fact that the high proficiency group were mostly heritage speakers, the same pattern should not appear when only non-heritage speakers are tested. Also, if heritage speakers have the same underlying representation as native speakers for class III Korean psych-predicates, the stimulus preference will appear more clearly in heritage speakers of more advanced Korean development in that stimulus reading itself will indicate the target-like representation. If, on the other hand, heritage speakers have an interlanguage grammar in which class III Korean psych-predicates are underlyingly misrepresented to be class II, replacing the nominative case particle 
in the critical construction with an accusative one will reveal how Korean psych-predicates and their required arguments are structured in heritage Korean grammar.

\section{References}

Ahn, H. (2017). The prosodic resolution of syntactic/semantic ambiguity: An exemplar-based account. Language Research, 53(3), 501-524.

Ahn, H. (2018). Prosody, syntax, and discourse: A three-way interaction. Korean Journal of Linguistics, 43(1), 73-100.

Akker, E., \& Cutler, A. (2003). Prosodic cues to semantic structure in native and nonnative listening. Bilingualism: Language and Cognition, 6(2), 81-96.

Barr, D. J., Levy, R., Scheepers, C., \& Tily, H. J. (2013). Random effects structure for confirmatory hypothesis testing: Keep it maximal. Journal of Memory and Language, 68(3), $255-278$.

Bates, D., Maechler, M., Bolker, B., \& Walker, S. (2015). Fitting linear mixed-effects models using 1me4. Journal of Statistical Software, 67(1), 1-48.

Belletti, A., \& Rizzi, L. (1988). Psych-verbs and $\theta$-theory. Natural Language \& Linguistic Theory, 6(3), 291-352.

Bogels, S., Schriefers, H., Vonk, W., Chwilla, D. J., \& Kerkhofs, R. (2009). The interplay between prosody and syntax in sentence processing: the case of subject- and object- control verbs. Journal of Cognitive Neuroscience, 22(5), 1036-1053.

Davies, M. (2008-). The Corpus of Contemporary American English (COCA): One billion words, 1990-2019. Available online at https://www.english-corpora.org/coca/

Flege, J. E. (2002). Interactions between the native and second language phonetic systems. In P. Burmeister, T. Piske, \& A. Rohde (Eds.), An integrated view of language development: Papers in honor of Henning Wode. Wissenschaftlicher Verlag Trier.

Flege, J. E., Birdsong, D., Bialystok, E., Mack, M., Sung, H., \& Tsukada, K. (2006). Degree of foreign accent in English sentences produced by Korean children and adults. Journal of Phonetics, 34(2), 153-175.

Flege, J. E., \& Wang, C. (1989). Native-language phonotactic constraints affect how well Chinese subjects perceive the word-final English /t/-/d/ contrast. Journal of Phonetics, 17(4), 299-315.

Flege, J. E., Yeni-Komshian, G. H., \& Liu, S. (1999). Age constraints on second language acquisition. Journal of Memory and Language, 41, 78-104.

Gordon, P. C., Grosz, B. J., \& Gilliom, L. A. (1993). Pronouns, names and the centering of attention in discourse. Cognitive Science, 17, 311-347.

Grosz, B. J., Joshi, A. K., \& Weinstein, S. (1995). Centering: A framework for modeling 
the local coherence of discourse. Computational Linguistics, 22(2), 203-225.

Hwang, H., \& Steinhauer, K. (2011). Phrase length matters: The interplay between implicit prosody and syntax in Korean "Garden Path" sentences. Journal of Cognitive Neuroscience, 23(11), 3555-3575.

Jackson, C. N., \& O'Brien, M. G. (2011). The interaction between prosody and meaning in second language speech production. Journal of the American Association of Teachers of German, 44(1), 1-11.

Jun, S.-A. (1993). The phonetics and phonology of Korean prosody. The Ohio State University.

Jun, S.-A. (2005). Intonational phonology of Seoul Korean revisited. UCLA Working Papers in Phonetics, 104, 14-25.

Jun, S.-A. (2007). The intermediate phrase in Korean: Evidence from sentence processing. In C. Gussenhoven \& T. Riad (Eds.), Tones and Tunes: Studies in Word and Sentence Prosody (pp. 143-167). Mouton de Gruyter.

Jun, S.-A. (2011). Prosodic markings of complex NP focus, syntax, and the pre-/post-focus string. In M. B. Washburn (Ed.), The 28th West Coast Conference on Formal Linguistics (pp. 214-230). Cascadilla Proceedings Project.

Jun, S.-A., \& Cha, J. (2015). High-toned [il] in Korean: Phonetics, intonational phonology, and sound change. Journal of Phonetics, 51, 93-108.

Jun, S.-A., \& Oh, M. (2000). Acquisition of second language intonation. The Sixth International Conference on Spoken Language Processing, Beijing, China.

Kuznetsova, A., Brockhoff, P. B., \& Christensen, R. H. B. (2017). lmerTest package: Tests in linear mixed effects models. Journal of Statistical Software, 82, 13.

Kwon, H. (2017). Language experience, speech perception and loanword adaptation: Variable adaptation of English word-final plosives into Korean. Journal of Phonetics, 60, 1-19.

Lado, R. (1957). Linguistics across cultures: Applied linguistics for language teachers. Ann Arbor, MI: University of Michigan Press.

Landau, I. (2010). The locative syntax of experiencers. MIT Press.

Matuschek, H., Kliegl, R., Vasishth, S., Baayen, H., \& Bates, D. (2017). Balancing type I error and power in linear mixed models. Journal of Memory and Language, 94, 305-315.

Morett, L. M., \& Macwhinney, B. (2012). Syntactic transfer in English-speaking Spanish learners. Bilingualism: Language and Cognition, 16(1), 132-151.

Scheidnes, M., Tuller, L., \& Delage, H. (2009). L1 transfer versus computational complexity in adult L2 French: Evidence from a comparison with deaf L1 French learners. In J. Crawford (Ed.), Proceedings of the 3rd Conference on Generative Approaches to Language Acquisition North America. Cascadilla Proceedings Project.

Slabakova, R. (2000). L1 transfer revisited: The L2 acquisition of telicity marking in English by Spanish and Bulgarian native speakers. Linguistics, 38(4), 739-770.

Trofimovich, P., \& Baker, W. (2006). Learning second language suprasegmentals: effect of L2 experience on prosody and fluency characteristics of L2 speech. Studies in Second Language Acquisition, 28, 1-30. 
Tsukada, K., Birdsong, D., Bialystok, E., Mack, M., Sung, H., \& Flege, J. (2005). A developmental study of English vowel production and perception by native Korean adults and children. Journal of Phonetics, 33(3), 263-290.

Wickham, H., Averick, M., Bryan, J., Chang, W., McGowan, L. D. A., François, R., Grolemund, G., Hayes, A., Henry, L., Hester, J., Kuhn, M., Pedersen, T. L., Miller, E., Bache, S. M., Müller, K., Ooms, J., Robinson, D., Seidel, D. P., Spinu, V., Takahashi, K., Vaughan, D., Wilke, C., Woo, K., \& Yutani, H. (2019). Welcome to the tidyverse. Journal of Open Source Software, 4.43, 1686.

Hyunah Ahn

Lecturer

Department of English Language and Literature

Seoul National University

1 Gwanakro, Gwanakgu, Seoul 08826, Korea

E-mail: prosodygal@snu.ac.kr

Received: July 4, 2020

Revised version received: August 3, 2020

Accepted: August 4, 2020 